В.Т. Ивашкин ${ }^{1}$, И.В. Маев$^{2}$, Д.И. Абдулганиева ${ }^{3}$, С.А. Алексеенко ${ }^{4}$, Н.Ю. Ивашкина², Н.В. Корочанская ${ }^{5}$, С.Н. Маммаев $^{6}$, Е.А. Полуэктова ${ }^{1}$, А.С. Трухманов ${ }^{1}$, Ю.П. Успенский ${ }^{7}$, В.В. Цуканов ${ }^{8}$, О.С. Шифринн ${ }^{1}$, О.Ю. Зольникова ${ }^{1}$, К.В. Ивашкин ${ }^{1}$, Т.Л. Лапина ${ }^{1}$, Р.В. Масленников ${ }^{1}$, А.И. Ульянин ${ }^{1, *}$

1 ФГАОУ ВО «Первый Московский государственный медицинский университет им. И.М. Сеченова» (Сеченовский университет) Министерства здравоохранения Российской Федерачии, Москва, Российская Федерация

${ }^{2}$ ФГБОУ ВО «Московский государственный медико-стоматологический университет им. А.И. Евдокимова»

Министерства здравоохранения Российской Федеращии, Москва, Российская Федерачия

${ }^{3}$ ФГБОУ ВО «Казанский государственный медицинский университет» Министерства здравоохранения

Российской Федеращии, Казань, Российская Федеращия

${ }_{4}^{4}$ ФГБОУ ВО «Дальневосточный государственный медищинский университет» Министерства здравоохранения

Российской Федерачии, Хабаровск, Российская Федерачия

${ }^{5}$ ФГБОУ ВО «Кубанский государственный медищинский университет» Министерства здравоохранения

Российской Федерачии, Краснодар, Российская Федерачия

${ }^{6}$ ФГБОУ ВО «Дагестанский государственный медицинский университет» Министерства здравоохранения

Российской Федерации, Махачкала, Российская Федерачия

${ }^{7}$ ФГБОУ ВО «Санкт-Петербургский государственный педиатрический медищинский университет»

Министерства здравоохранения Российской Федеращии, Санкт-Петербург, Российская Федерация

${ }^{8}$ ФГБНУ «Федеральный исследовательский центр “Красноярский научный чентр Сибирского отделения

Российской академии наук”», Научно-исследовательский институт медицинских проблем Севера

Сибирского отделения РАН, Красноярск, Российская Федерачия

Цель: представить практические рекомендации по применению пробиотиков для лечения и профилактики заболеваний гастроэнтерологического профиля у взрослых.

Основные положения. Пробиотики - это живые микроорганизмы, которые приносят пользу здоровью организма хозяина при введении в адекватных количествах. К основным функциям пробиотиков относятся: поддержка колонизационной резистентности, метаболизм пищевых субстратов и утилизация конечных метаболитов, продукция субстратов, необходимых для макроорганизма, а также регуляция местного и адаптивного иммунного ответа. Пробиотики могут быть зарегистрированы на территории РФ как биологически активные добавки (БАД) к пище или как лекарственные средства (ЛС) в соответствии с микробиологическими стандартами и законодательными требованиями РФ. К пробиотикам, зарегистрированным на территории РФ в качестве БАД для взрослых, относятся бактерии родов Lactobacillus, Bifidobacterium, Enterococcus, Pediococcus, Lactococcus, Streptococcus, Bacillus, Escherichia и грибы рода Saccharomyces, к пробиотикам, зарегистрированным в качестве ЛС, - бактерии рода Lactobacillus, Bifidobacterium, Escherichia и Enterococcus и грибы рода Saccharomyces. В состав отдельных зарегистрированных на территории РФ пробиотиков включены пробиотические штаммы, подтвердившие свою эффективность для профилактики и лечения антибиотик-ассоциированной диареи, профилактики C. difficile-ассоциированной болезни, эрадикации инфекции H. pylori, а также для лечения синдрома раздраженного кишечника и функционального запора.

Заключение. Клиническая эффективность пробиотиков зависит от входящих в его состав пробиотических штаммов и подтверждается путем сравнительного анализа результатов надлежащих клинических 
исследований. Не во всех пробиотиках, зарегистрированных на территории РФ в качестве БАД или ЛС, идентифицирован штамм, что не гарантирует развитие ожидаемого клинического эффекта.

Ключевые слова: пробиотик, пробиотический штамм, острая диарея, антибиотик-ассоциированная диарея, C. difficile-ассоциированная болезнь, эрадикация H. pylori, воспалительные заболевания кишечника, язвенный колит, болезнь Крона, паучит, синдром раздраженного кишечника, функциональный запор

Конфликт интересов: авторы заявляют об отсутствии конфликта интересов.

Для цитирования: Ивашкин В.Т., Маев И. В., Абдулганиева Д. И., Алексеенко С. А., Ивашкина Н. Ю., Корочанская Н. В., Маммаев С. Н., Полуэктова Е. А., Трухманов А. С., Успенский Ю. П., Цуканов В. В., Шифрин О. С., Зольникова О. Ю., Ивашкин К. В., Лапина Т. Л., Масленников Р. В., Ульянин А. И. Практические рекомендации Научного сообщества по содействию клиническому изучению микробиома человека (НСОИМ) и Российской гастроэнтерологической ассоциации (РГА) по применению пробиотиков для лечения и профилактики заболеваний гастроэнтерологического профиля у взрослых. Российский журнал гастроэнтерологии, гепатологии, колопроктологии. 2020;30(2):76-89. https://doi.org/10.22416/1382-43762020-30-2-76-89

\section{Practical Recommendations of Scientific Society for the Study of Human Microbiome and Russian Gastroenterological Association (RGA) for Probiotics in Treatment and Prevention of Gastroenterological Diseases in Adults}

Vladimir T. Ivashkin'1, Igor V. Mayev², Diana I. Abdulganieva ${ }^{3}$, Sergey A. Alekseenko4, Natalya Yu. Ivashkina², Natalya V. Korochanskaya ${ }^{5}$, Suleyman N. Mammaev ${ }^{6}$, Elena A. Poluektova ${ }^{1}$, Alexander S. Trukhmanov ${ }^{1}$, Yury P. Uspensky7, Vladislav V. Tsukanovㄹ, Oleg S. Shifrin ${ }^{1}$, Oxana Yu. Zolnikova ${ }^{1}$, Konstantin V. Ivashkin ${ }^{1}$, Tatiana L. Lapina ${ }^{1}$, Roman V. Maslennikov ${ }^{1}$, Anatoly I. Ulyanin ${ }^{1, *}$

${ }^{1}$ I.M. Sechenov First Moscow State Medical University (Sechenov University), Moscow, Russian Federation

${ }^{2}$ A.I. Yevdokimov Moscow State University of Medicine and Dentistry, Moscow, Russian Federation

${ }^{3}$ Kazan State Medical University, Kazan, Russian Federation

${ }^{4}$ Far Eastern State Medical University, Khabarovsk, Russian Federation

${ }^{5}$ Kuban State Medical University, Krasnodar, Russian Federation

${ }^{6}$ Dagestan State Medical University, Makhachkala, Russian Federation

${ }^{7}$ St. Petersburg State Pediatric Medical University, St. Petersburg, Russian Federation

${ }^{8}$ Federal Research Centre "Krasnoyarsk Scientific Centre of the Siberian Branch of the Russian Academy of Sciences" Scientific Research Institute of Medical Problems of the North, Krasnoyarsk, Russian Federation

Aim. To provide practical recommendations on the use of probiotics for the treatment and prevention of gastroenterological diseases in adults.

General provisions. Probiotics are living microorganisms that benefit the health of the host when administered in adequate amounts. The main functions of probiotics include the support for colonisation resistance, the metabolism of food substrates and utilisation of end metabolites, the production of substrates necessary for the macro-organism, as well as the regulation of local and adaptive immune responses. Probiotics can be registered in the Russian Federation as biologically active food additives (BAFA) or as pharmaceutical products (drugs) in accordance with the microbiological standards and legislative requirements of the Russian Federation. The probiotics registered in the Russian Federation as BAFA for adults include bacteria of the Lactobacillus, Bifidobacterium, Enterococcus, Pediococcus, Lactococcus, Streptococcus, Bacillus, and Escherichia genera, and fungi of the Saccharomyces genus; probiotics registered as drugs - bacteria of Lactobid, Lactobacid, Escherichia and Enterococcus genera and fungi of the Saccharomyces genus. Some probiotics registered in the Russian Federation include probiotic strains that have proved to be effective for the prevention and treatment of antibiotic-associated diarrhea, the prevention of $C$. difficile-associated disease, the eradication of $H$. pylori infection, as well as for the treatment of irritable bowel syndrome and functional constipation.

Conclusions. The clinical efficacy of probiotics depends on the probiotic strains included in their composition and is confirmed by a comparative analysis of the results of appropriate clinical studies. Not all probiotics registered in the Russian Federation as BAFA or drugs contain bacterial or fungal strains; as a result, the expected clinical effect may not be achieved.

Keywords: probiotic, probiotic strain, acute diarrhea, antibiotic-associated diarrhea, C. difficile-associated disease, $H$. pylori eradication, inflammatory bowel disease, ulcerative colitis, Crohn's disease, pouchitis, irritable bowel syndrome, functional constipation

Conflict of interest: the authors declare no conflict of interest.

For citation: Ivashkin V.T., Mayev I.V., Abdulganieva D.I., Alekseenko S.A., Ivashkina N.Yu., Korochanskaya N.V., Mammaev S.N., Poluektova E.A., Trukhmanov A.S., Uspensky Yu.P., Tsukanov V.V., Shifrin O.S., Zolnikova O.Yu., Ivashkin K.V., Lapina T.L., Maslennikov R.V. , Ulyanin A.I. Practical Recommendations of Scientific Society for the Study of Human Microbiome and Russian Gastroenterological Association (RGA) for Probiotics in Treatment and Prevention of Gastroenterological Diseases in Adults. Russian Journal of Gastroenterology, Hepatology, Coloproctology. 2020;30(2):76-89. https://doi.org/10.22416/1382-43762020-30-2-76-89 


\section{1. Пробиотики}

\section{1 Определение}

Пробиотики - это живые микроорганизмы, которые приносят пользу здоровью организма хозяина при введении в адекватных количествах [1].

В качестве пробиотиков чаще всего применяются бактерии родов Lactobacillus, Bifidobacterium, Streptococcus и Bacillus, некоторые виды E. coli и грибы рода Saccharomyces [2].

Помимо пробиотиков на здоровье человека также оказывают влияние пребиотики. К пребиотикам относятся ферментируемые микробиотой субстанции, которые приводят к специфическим изменениям в составе и/или активности желудочно-кишечной микробиоты, принося таким образом пользу здоровью организма хозяина. К наиболее важным группам пребиотиков относят фруктоолигосахариды и галактоолигосахариды [3].

Продукты, имеющие в своем составе пробиотические штаммы и пребиотики, носят название $\mathrm{cuн}^{-}$ биотиков [4].

\section{2 Роды, виды и штаммы пробиотических продуктов}

Пробиотический штамм идентифицируется на уровне рода, вида и имеет буквенное, цифровое или буквенно-цифровое обозначение, например: Lactobacillus casei DN-114 001 или Lactobacillus rhamnosus GG. Определенный штамм пробиотика должен обладать заявленными эффектами при его применении, подтвержденными клиническими исследованиями.

\section{3 Механизм действия пробиотиков}

Несмотря на существенное разнообразие и широкое применение пробиотических штаммов, их механизмы действия окончательно не изучены. Функции пробиотиков во многом схожи с таковыми у представителей нормальной кишечной микробиоты человека, однако их эффект может различаться в зависимости от рода, вида или даже штамма. Ниже представлены основные механизмы действия и функции пробиотиков.

\section{Поддержание колонизационной резистентности}

В основе колонизационной резистентности лежит способность пробиотических штаммов предотвращать колонизацию желудочно-кишечного тракта (ЖКТ) условно-патогенными и патогенными микроорганизмами за счет угнетения их активности и способности к размножению вследствие конкуренции за питательные вещества, а также путем синтеза ряда антибактериальных метаболитов, активных в отношении патогенных бактерий (органические кислоты, бактериоцины, амины и т.д.) [5].

\section{Метаболизм пищевых субстратов и утилизация конечных продуктов метаболизма человека}

Находясь в просвете кишечника, пробиотики метаболизируют компоненты пищи (например, растительные волокна) и некоторые другие субстанции (например, первичные желчные кислоты) за счет наличия специфических ферментов, отсутствующих у человека. К таким ферментам, в частности, относятся $\beta$-галактозидаза (осуществляет гидролиз $\beta$-галактозидов в моносахариды) и гидролаза желчных солей (участвует в деконъюгации желчных кислот и их солей) [6].

\section{Продукиия метаболитов, необходимых для макроорганизма}

В процессе своей жизнедеятельности пробиотические штаммы осуществляют синтез метаболитов, которые поступают в системный кровоток и участвуют в поддержании гомеостаза макроорганизма. В первую очередь к таким метаболитам относятся короткоцепочечные жирные кислоты (КЦЖК) - ацетат, пропионат и бутират, поддерживающие регуляцию энергетического гомеостаза (особенно в колоноцитах), а также служат сигнальными молекулами для клеток иммунной системы, определяя их дифференцировку и противовоспалительную активность [7]. В ходе своей жизнедеятельности пробиотические микроорганизмы продуцируют различные медиаторы - допамин (участвует в формировании мотивации и поведенческих реакций, является предшественником норадреналина и адреналина), норадреналин (регулирует процессы в центральной нервной системе (ЦНС), ответственные за бодрствование, запоминание, обучение и внимание), серотонин (регулирует желудочно-кишечную секрецию и перистальтику, вазоконстрикцию и психоэмоциональный статус), гамма-аминомасляную кислоту (основной ингибиторный нейротрансмиттер в ЦНС), ацетилхолин (основной медиатор в холинергических нервных путях) и гистамин (медиатор гистаминовых рецепторов в клетках ЦНС, ЖКТ, сердечно-сосудистой, дыхательной и иммунной систем) [8].

Кроме этого, пробиотики синтезируют такие незаменимые для макроорганизма метаболиты, как, например, триптофан [8] и витамины группы В, выполняющие роль коферментов множества биохимических процессов в организме человека рибофлавин (витамин $\mathrm{B}_{2}$ ), кобаламин (витамин $\mathrm{B}_{12}$ ) и фолиевую кислоту (витамин $\mathrm{B}_{9}$ ) [9].

\section{Регулячия местного и адаптивного имммуного ответа}

Взаимодействие компонентов пробиотических бактерий с иммунокомпетентными клетками хозяина прямо или опосредованно ведет к активации местного и системного противовоспалительного иммунного ответа за счет стимуляции синтеза 
противовоспалительных цитокинов (в основном Ил-4 и Ил-10). Повышенный уровень противовоспалительных цитокинов также определяет направленность дифференцировки регуляторных иммунных клеток (в первую очередь Т-регуляторных лимфоцитов), что проявляется угнетением провоспалительных реакций и поддержанием противовоспалительного иммунного ответа [10].

\section{2. Медицинские требования к пробиотикам}

2.1 Регламент регистрации пробиотиков в РФ

Пробиотики могут быть зарегистрированы на территории РФ в качестве биологически активных добавок к пище (БАД) или в качестве лекарственных средств (ЛС) в соответствии с законодательными актами Российской Федерации.

Безопасность пробиотиков, зарегистрированных как в качестве БАД, так и в качестве ЛС, должна соответствовать строгим микробиологическим стандартам, которые определяются Едиными санитарно-эпидемиологическими и гигиеническими требованиями к товарам, подлежащим санитарноэпидемиологическому надзору, и контролируются Роспотребнадзором [11].

Биологически активные добавки к пище (БАД) - это природные и (или) идентичные природным биологически активные вещества, а также пробиотические микроорганизмы, предназначенные для употребления одновременно с пищей или введения в состав пищевой продукчии [12].

Для реализации пробиотиков на территории РФ и Евразийского экономического союза (ЕЭС) в качестве БАД пробиотики должны соответствовать гигиеническим требованиям безопасности пищевой продукции, установленным в Приложениях 1, 2, 3 технического регламента Таможенного союза «О безопасности пищевой продукции» (ТР TC $021 / 2011)$ [13].

После подтверждения соответствия образцов указанным выше гигиеническим требованиям безопасности пищевой продукции принимается решение о государственной регистрации БАД с внесением в Единый реестр свидетельств о государственной регистрации, который контролируется Федеральной службой по надзору в сфере защиты прав потребителей и благополучия человека (Роспотребнадзор) [12].

В целях предупреждения действий, вводящих в заблуждение потребителей, Роспотребнадзором утверждена и внесена в Единый реестр систем добровольной сертификации (ДСС) «Система добровольной сертификации биологически активных добавок к пище, пищевых добавок и пищевых продуктов, полученных из генетически модифицированных источников» - в рамках которой предусматривается подтверждение качества про- дукции в соответствии с постановлением СанПиН 2.3.2.1290-03 «Гигиенические требования к организации производства и оборота биологически активных добавок к пище (БАД)». ДСС для пробиотиков, зарегистрированных в качестве БАД, подтверждает эффективность и соответствие свойств пробиотика, декларированных производителем или импортером. Нанесение информации на этикетку БАД (и/или на потребительскую (вторичную) упаковку БАД, инструкцию к применению, вкладыш и т.д.) об эффективности использования пробиотика в качестве БАД возможно только после проведения добровольной сертификации БАД и наличия вышеуказанного сертификата соответствия.

При регистрации пробиотиков в качестве БАД на территории Российской Федерации информация на этикетке должна включать:

- надпись: «Биологически активная добавка к пище»;

- название: «БАД к пище»;

- надпись: «Не является лекарством»;

- ингредиентный состав вместе со вспомогательными компонентами;

- форму выпуска и упаковки;

- область применения, с указанием, источником каких пищевых биологически активных вешеств является БАД;

- прочент от адекватного уровня потребления;

- дозировку;

- рекомендачии по применению;

- противопоказания;

- условия хранения, срок годности;

- сведения о возможности реализации в аптечных учреждениях и спечиализированных магазинах или отделах продовольственных магазинов по продаже диетических продуктов;

- номер технических условий производства ( для отечественных БАД);

- название организачии-изготовителя и ее юридический адрес (для импортируемых на территорию РФ продуктов - страна происхождения и наименование фирмь-изготовителя);

- номер и дату выдачи свидетельства о государственной регистрации;

- реквизиты и контактный телефон организачии, уполномоченной принимать претензии от потребителей.

Регистрация пробиотика в качестве ЛС осуществляется согласно требованиям Федерального закона Российской Федерации № 61-Ф3 «Об обращении лекарственных средств» [14]. Для пробиотиков, зарегистрированных как ЛС, применимы правила оборота ЛС, определенные приказом Министерства здравоохранения Российской Федерации от 11 июля 2017 г. № 403н «Об утверждении правил отпуска лекарственных препаратов для медицинского применения, в том числе 
иммунобиологических лекарственных препаратов, аптечными организациями, индивидуальными предпринимателями, имеющими лицензию на фармацевтическую деятельность» [15].

Пробиотик, зарегистрированный в качестве ЛС, идентифицируется как иммунобиологический лекарственный препарат, который содержит живые или инактивированные апатогенные микроорганизмы (эубиотики), обладающие антагонистической активностью в отношении патогенных и условнопатогенных бактерий. Такие пробиотики должны соответствовать фармакопейным требованиям получения производственного штамма и его посевного материала для формирования производственной биомассы, а также требованиям качества ЛС для определенной лекарственной формы [16].

Зарегистрированный в качестве ЛС пробиотик должен быть отнесен к определенной фармакотерапевтической группе (пробиотик, эубиотик, противодиарейное средство, пробиотик или эубиотик из группы медицинских иммунобиологических препаратов (МИБП-пробиотик или МИБП-эубиотик)) и классифицироваться в соответствии с анатомо-терапевтической химической классификацией (АТХК). Зарегистрированные в качестве ЛС на территории РФ пробиотики имеют следующие коды АТХК: сахаромицеты Boulardii (A07FA02), противодиарейные микроорганизмы (А07FA), лактобациллы (G01AX14), микроорганизмы, продуцирующие молочную кислоту (А07FA01), и микроорганизмы, продуцирующие молочную кислоту, в комбинации с другими препаратами (A07FA51). Некоторые из зарегистрированных в качестве ЛС пробиотиков могут иметь одинаковый состав, но при этом отличаться по АТХК и принадлежности к фармакотерапевтической группе.

\section{2 Дозы и эффективность пробиотиков}

Рекомендуемая минимальная эффективная суточная доза пробиотиков должна составлять $10^{8}-$ $10^{9}$ колониеобразующих единиц (КОЕ) [17], однако эффективная суточная доза пробиотика может различаться в зависимости от пробиотического штамма и формы выпуска.

Определение оптимальной дозировки должно основываться на результатах клинических исследований, демонстрирующих развитие ожидаемых благоприятных эффектов конкретного штамма пробиотика в указанной дозе.

Сохранение жизнеспособности штаммов в указанном количестве до конца срока годности пробиотика также является необходимым условием для его эффективного применения.

Немаловажным фактором, определяющим выживаемость пробиотических микроорганизмов и поступление достаточного количества КОЕ в толстую кишку, является агрессивная среда верхних отделов пищеварительного тракта - высокая кислотность, пищеварительные ферменты и соли желчных кислот [18]. Инструментом скрининга для определения выживаемости потенциальных пробиотиков в верхних отделах ЖКТ служат тесты in vitro, воспроизводящие условия его проксимальных отделов и способные помочь определению оптимального количества КОЕ в пробиотике.

Несмотря на многообразие лекарственных форм (капсула, таблетки, саше, назальные спреи и прочие), преимущественной формой доставки пробиотических штаммов в толстую кишку служат капсулы и микрокапсулы, изготовленные из синтетических, полусинтетических или натуральных полимеров, обеспечивающие сохранность пробиотических штаммов в агрессивной среде верхних отделов пищеварительного тракта и обеспечивающие последовательное их высвобождение на протяжении ЖКТ в метаболически активном состоянии [19, 20].

В пробиотиках последнего поколения пробиотические штаммы могут находиться внутри капсулы в виде биопленок. Такая форма сохранения штаммов увеличивает срок годности пробиотика, а также обеспечивает высвобождение достаточного количества КОЕ непосредственно в толстой кишке [21].

Необходимо отметить, что некоторые пробиотики, выпускающиеся в иных формах (порошки, растворы, саше и пр.), доказали свою эффективность и безопасность в клинических исследованиях надлежащего качества.

\section{3. Обзор пробиотических штаммов, зарегистрированных в РФ}

К пробиотикам, зарегистрированным на территории РФ в качестве БАД для взрослых, в состав действующих веществ которых не входят пребиотические добавки (инулин, пектин, лактоза, фруктоолигосахариды и пр.), витамины и микроэлементы, иммуноглобулины, метаболиты (в том числе нуклеотиды) или продукты жизнедеятельности микроорганизмов, относятся бактерии родов Lactobacillus, Bifidobacterium, Enterococcus, Pediococcus, Lactococcus, Streptococcus, Bacillus, Escherichia и грибы рода Saccharomyces. Пробиотики, в составе которых содержатся данные микроорганизмы, перечислены в Едином реестре свидетельств о государственной регистрации и разрешены к продаже на территории РФ (по состоянию на октябрь 2019 г.) (табл. 1).

Пробиотики, зарегистрированные на территории РФ в качестве ЛС, представлены бактериями рода Lactobacillus, Bifidobacterium, Escherichia u Enterococcus, а также грибками рода Saccharomyces (табл. 2).

\section{4. К линическое применение}

Не все пробиотики, зарегистрированные на территории РФ в качестве БАД или ЛС, имеют указание штамма. В таком случае развитие ожидаемого эффекта от пробиотика не гарантировано. 
Таблища 1. Микроорганизмы в составе пробиотиков, зарегистрированных на территории РФ в качестве БАД

Table 1. Microorganisms in the composition of probiotics registered in RF as BAFA

\begin{tabular}{|c|c|c|}
\hline $\begin{array}{c}\text { Род } \\
\text { Genus }\end{array}$ & $\begin{array}{c}\text { Вид } \\
\text { Species }\end{array}$ & $\begin{array}{l}\text { Штамм } \\
\text { Strain }\end{array}$ \\
\hline \multirow{15}{*}{ Lactobacillus } & acidophilus & 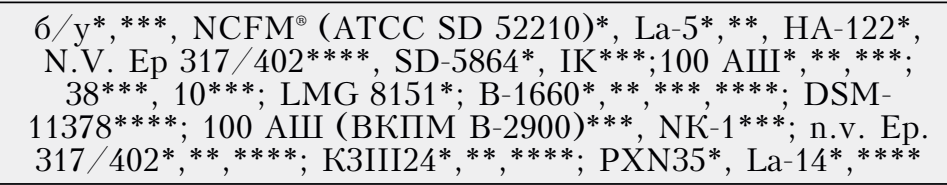 \\
\hline & bulgaricus & б/y*, Selur 6*, Selur 19*; PXN 39* \\
\hline & breve & $6 / y^{*}$ \\
\hline & brevis & б/y**, LMG 27275* \\
\hline & casei & $\begin{array}{c}\text { б/y**,***, HA-108*, } 431^{\mathrm{TM} * * * *}, \mathrm{C \sigma}^{* * *}, \mathrm{C} 1 * * * ; \mathrm{C}-1 \text { (ВКПМ } \\
\text { В-3960)***; PXN } 37^{*}\end{array}$ \\
\hline & crispatus & LMG 9479* \\
\hline & delbrueckii subsp. bulgaricus & LbY-27 ${ }^{\oplus *}$ \\
\hline & fermentum & 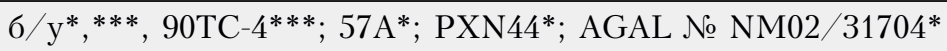 \\
\hline & gasseri & Selur $20^{*} ; 57 \mathrm{C}^{*} ; \mathrm{KS}-13^{*} ; \mathrm{LAC}-343^{*}$ \\
\hline & helveticus & $\sigma / \mathrm{y}^{*},{ }^{* *}$, Lafti L10*; B-842*,**,***,****; PXN $45^{*}$ \\
\hline & paracase $i$ & DSM $11358^{* * * *} ;$ L. CASEI $431^{\oplus *} ;$ Lpc-37 (ATCC SD 5275)* \\
\hline & plantarum & 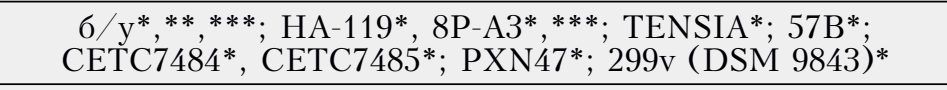 \\
\hline & reuteri & $6 / \mathrm{y}^{* *},{ }^{* * *},{ }^{* * * *} ; \mathrm{DSM} 17938^{* * * * *},{ }^{* * * *} ; \mathrm{NCIMB} 30351^{* * *}$ \\
\hline & rhamnosus & 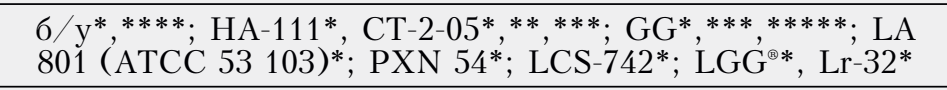 \\
\hline & salivarius & б/y*, DSM $11361^{* * * *} ; \mathrm{PXN} 57^{*}$ \\
\hline \multirow{8}{*}{$\begin{array}{l}\text { Bifidobacte- } \\
\text { rium }\end{array}$} & adolescentis & $6 / \mathrm{y}^{* * * * *}$ \\
\hline & animalis & $\mathrm{Bb}-12 *, * *$ \\
\hline & animalis ssp. lactis & $\mathrm{Bb}-12^{*}, * * * * ; \mathrm{PXN} 63^{*}$ \\
\hline & bifidum & 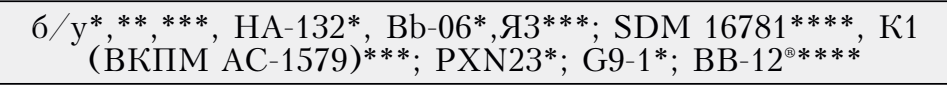 \\
\hline & breve & НА-129*; PXN 25*; YА-129*; M16V Тип T* \\
\hline & infantis & $6 / \mathrm{y}^{*},{ }^{* * *}, * * * * ; \mathrm{PXN} 27^{*} ; \mathrm{M}-63^{*} ; \mathrm{BB}-02^{\mathrm{rM} * * * *}$ \\
\hline & longum (ssp. longum) & 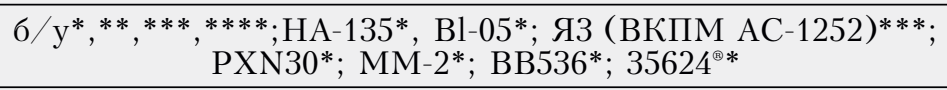 \\
\hline & lactis & $\begin{array}{c}/ \mathrm{y}^{*}, \mathrm{Bl}-04(\mathrm{ATCCSD} 5219)^{*} ; \mathrm{Bi}-07(\mathrm{ATCC} \text { SD } 5220)^{*} ; \\
\text { DSM } 11360^{* * * *}, \mathrm{DSM} 16782^{* * * *}\end{array}$ \\
\hline \multirow{2}{*}{ Lactococcus } & lactis & $\mathrm{Б} \mathrm{A}-1 *, * *, * * *, * * * *$ \\
\hline & delbrueckii subsp. bulgaricus & $\sigma / \mathrm{y}^{* * * *}$ \\
\hline Bacillus & amyloliquefaciens & $\begin{array}{l}\text { ВКПМ В-10642 (DSM 24614)*,****; ВКПМ В-10643 (DSM } \\
24615)^{* * * * *}\end{array}$ \\
\hline $\begin{array}{l}\text { Propionibac- } \\
\text { terium }\end{array}$ & $\begin{array}{l}\text { freudenreichii ssp. } \\
\text { Shermanii }\end{array}$ & БА- $1 *,{ }^{* *},{ }^{* * *},{ }^{* * * *} ;$ БА $-2 *,{ }^{* *},{ }^{* * *},{ }^{* * * *}$ \\
\hline \multirow[t]{2}{*}{ Streptococcus } & thermophilus & 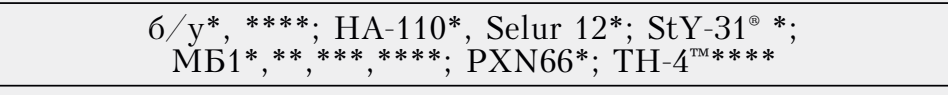 \\
\hline & salivarius & $\mathrm{K} 12^{* *}$ \\
\hline Pediococcus & acidilactici & CETC7483* \\
\hline Saccharomyces & cerevisiae & $\sigma / \mathrm{y}^{*}$ \\
\hline
\end{tabular}

Примечание: $6 /$ у - без указания штамма; * - капсулы; ** - таблетки; *** - жидкость во флаконах; **** - порошок; ***** - жевательные таблетки.

Note: $\sigma / \mathrm{y}-$ strain not indicated; ${ }^{*}-$ capsules; ${ }^{*}-$ pills; ${ }^{* * *}-$ liquid in vials; ${ }^{* * *}-$ powder; ${ }^{* * * *}-$ chewing pills. 
Таблища 2. Микроорганизмы в составе пробиотиков, зарегистрированных на территории РФ в качестве ЛС

Table 2. Microorganisms in the composition of probiotics registered in $\mathrm{RF}$ as drugs

\begin{tabular}{|c|c|c|}
\hline $\begin{array}{c}\text { Род } \\
\text { Genus }\end{array}$ & $\begin{array}{c}\text { Вид } \\
\text { Species }\end{array}$ & $\begin{array}{l}\text { Штамм } \\
\text { Strain }\end{array}$ \\
\hline \multirow{6}{*}{ Lactobacillus } & acidophilus & 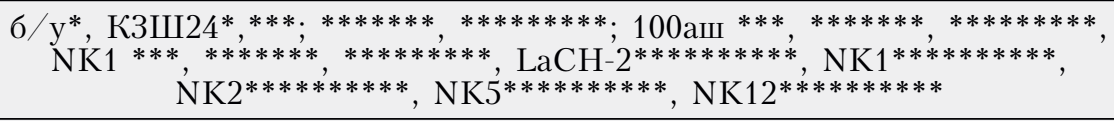 \\
\hline & casei & $\sigma / \mathrm{y}^{* * * * * * * * * *}$ \\
\hline & doderleini & $\sigma / \mathrm{y} * * * * * * * * * *$ \\
\hline & fermentum & $90 \mathrm{~T}-\mathrm{C} 4 * * *$ \\
\hline & plantarum & $6 / \mathrm{y}^{*}, * * * * ; 8 \mathrm{P}-\mathrm{A} 3^{*},{ }^{* * *}, * * * * * * * * *$ \\
\hline & rhamnosus & $\sigma / \mathrm{y}^{* * * * * * * * * *}$ \\
\hline \multirow{3}{*}{ Bifidobacterium } & bifidum & 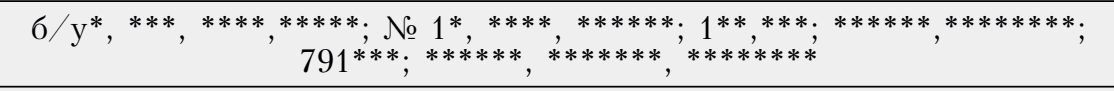 \\
\hline & infantis & $\sigma / \mathrm{y}^{*}$ \\
\hline & longum & $\sigma / \mathrm{y}^{* * * * * * * * *}$ \\
\hline Escherichia & coli & $\mathrm{M}-17^{* *}$ \\
\hline Enterococcus & faecium & $\sigma / \mathrm{y}^{*}, * * * * * * * * *$ \\
\hline Saccharomyces & boulardii & $\mathrm{CNCM} \mathrm{I-745^{* } , * * * * * * * * * * *}$ \\
\hline
\end{tabular}

Примечание: $\sigma / \mathrm{y}$ - без указания штамма; ${ }^{*}-$ капсулы; ** - лиофилизат для приготовления суспензии для приема внутрь; *** - лиофилизат для приготовления суспензии для приема внутрь и местного применения; **** - порошок для приема внутрь; ***** - порошок для приема внутрь и местного применения; ****** - суппозитории ректальные и вагинальные; ****** - таблетки; ******** - лиофилизат для приготовления раствора для приема внутрь и местного применения; $* * * * * * * *-$ капсулы кишечнорастворимые; $* * * * * * * * *-$ суппозитории вагинальные; ********** - капсулы вагинальные; $* * * * * * * * * *$ - порошок для приготовления суспензии для приема внутрь; $* * * * * * * * * * *-$ суспензия для приема внутрь.

Note: $\sigma / y-$ strain not indicated; * - capsules; ${ }^{*}$ - lyophilisate for the preparation of suspension for oral administration; $* * *$ - lyophilisate for the preparation of suspension for oral administration and local administration; **** _ powder for oral administration; ${ }^{* * * *}$ - powder for oral administration and local administration; $* * * * * *$ - rectal and vaginal suppositories; $* * * * * * *$ - pills; $* * * * * * * *$ - lyophilisate for the preparation of solution for oral administration and local administration; $* * * * * * * *$ - enterosoluble capsules; ${ }^{* * * * * * * * *}$ _ vaginal suppositories; ${ }^{* * * * * * * * * *}$ _ vaginal capsules; ${ }^{* * * * * * * * * * *}$ _ powder for the preparation of suspension for oral administration; $* * * * * * * * * * *$ - suspension for oral administration.

Однако следует отметить, что эффективность и безопасность отдельных пробиотических составов, содержащих определенные пробиотические микроорганизмы без указания штаммов, доказаны при тех или иных нозологических формах в клинических исследованиях надлежащего качества.

\section{1 Уровни доказательности}

Определение эффективности определенного пробиотического штамма при тех или иных заболеваниях или состояниях осуществляется путем сравнительного анализа результатов надлежащих клинических исследований (табл. 3) [22].

Эффективность клинического применения пробиотиков, зарегистрированных в РФ для лечения и профилактики заболеваний гастроэнтерологического профиля, представлена в таблицах ниже.

\section{2 Лечение и профилактика диареи}

4.2.1 Лечение острой диареи (табл. 4)

4.2.2 Профилактика антибиотикоассоциированной диареи (ААД) (табл. 5)

\subsection{3 Профилактика C.difficile- ассоциированной болезни (табл. 6)}

\section{3 Эрадикация инфекции $\boldsymbol{H}$. pylori}

Назначение пробиотиков уменьшает частоту побочных эффектов антибактериальной терапии при проведении эрадикации инфекции $H$. pylori (табл. 7). Назначение пробиотиков до, во время, а также в течение 2 недель после эрадикации оказывает положительное влияние на эффективность терапии, при этом наиболее эффективной комбинацией является сочетание пробиотиков с четырехкомпонентной терапией с препаратами висмута [29].

\section{4 Лечение и профилактика воспалительных заболеваний кишечника (ВЗК)}

\subsection{1 Язвенный колит}

Нет зарегистрированных в РФ штаммов

\subsection{2 Паучит}

Нет зарегистрированных в РФ штаммов 


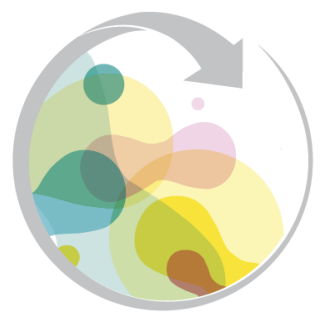

\section{Флориоза}

\section{микрофлоре польза}

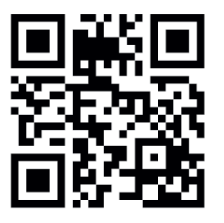

ПОСЕТИТЕ САЙТ Florioza.ru

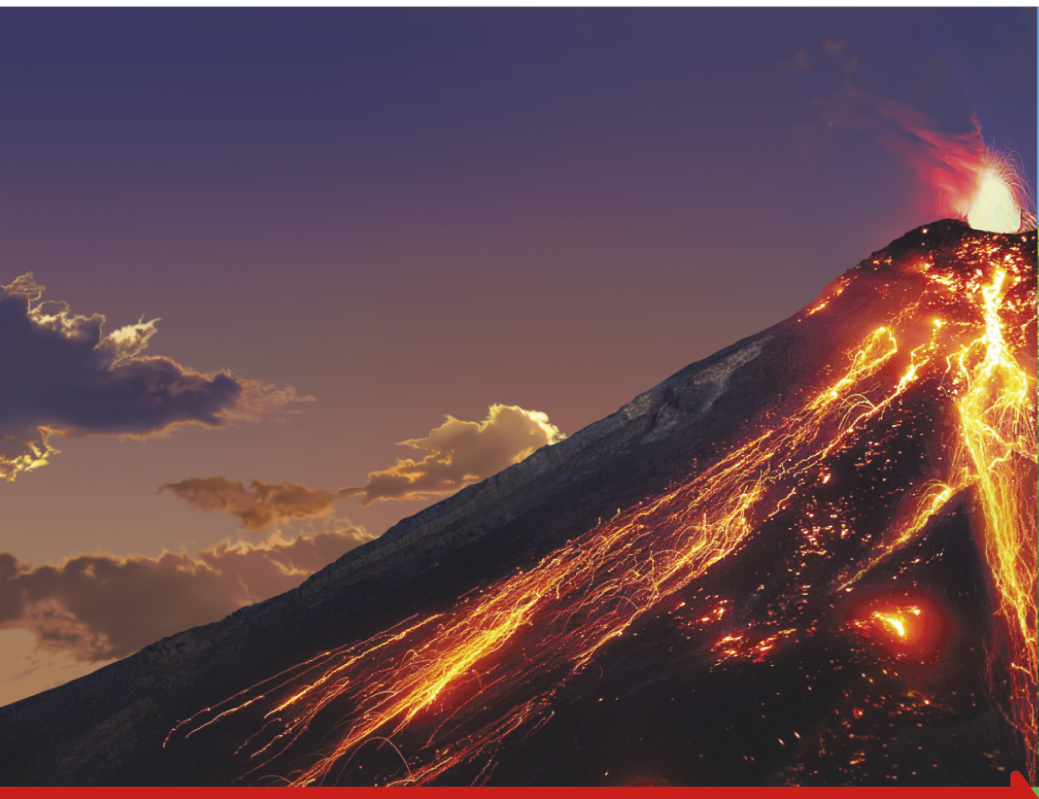

КОГАА МИКРОФЛОРЕ УГРОЗА

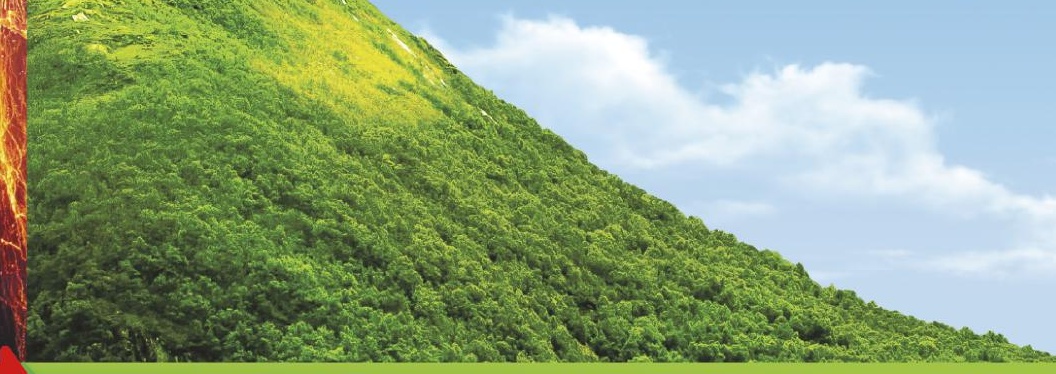

СОВРЕМЕННЫЙ ИТАЛЬЯНСКИЙ ПРЕ- И ПРОБИОТИК ДЛЯ ФИЗИОЛОГИЧНОГО ВОССТАНОВЛЕНИЯ МИКРОФЛОРЫ

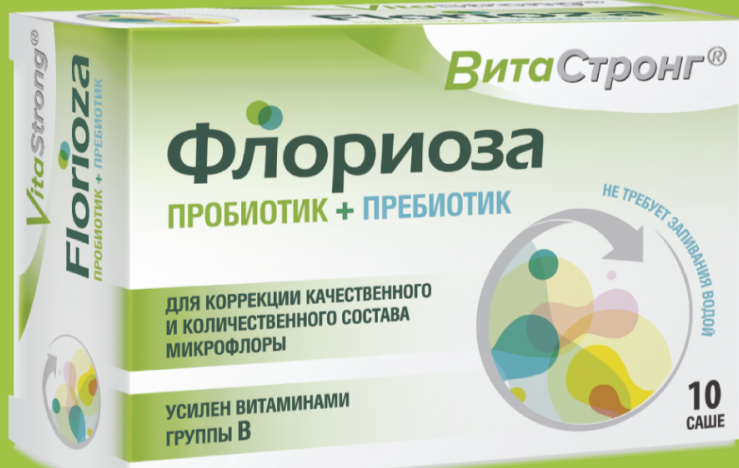

(1) ОСОБЫЕ ПРОБИОТИЧЕСКИЕ ШТАММЫ БИФИАО- И ЛАКТОБАКТЕРИЙ

(2) ВЫСОКАЯ ДОЗИРОВКА ПРОБИОТИЧЕСКИХ БАКТЕРИЙ²

(3) СОДЕР КИТ ИНУЛИН 800 МГ' $^{1}$

4 ВИТАМИНЫ ГРУППЫ В

(5) РАЗРАБОТАНО И ПРОИЗВЕАЕНО В ИТАЛИИ

Источник: 1. Листок-вкладыш для биологически активной добавки к пище Флориоза Витастронг. 2. Сравнительный вывод сделан на основании изучения составов пробиотических препаратов, представленных на фармацевтическом рынке РФ, IMS Health, сентябрь 2019 г.

Свидетельство о государственной регистрации: № RU.77.99.11.003.Е.001326.04.19 от 09.04.2019 г

Представительство компании "Сан Фармасьютикал Индастриз Лтд" в России. Адрес: Россия, 107023, г. Москва, ул. Электрозаводская, д. 27, стр. 8 , офисы 29, 30. Тел.: +7 (495) 234-56-11 www.sunpharma.com

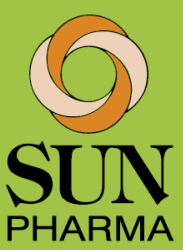




\section{КАЛЕЙДОСКОП ПРОБИОТИКОВ Из ЕвроПЫ}

\section{для нормализации работы кишечника}

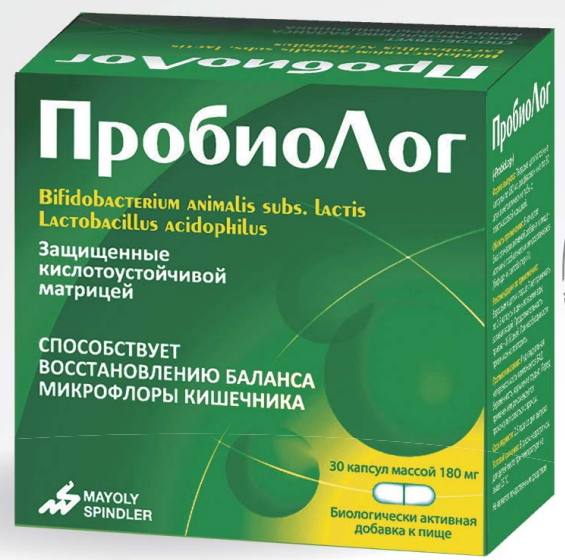

от 1 млрд. бактерий

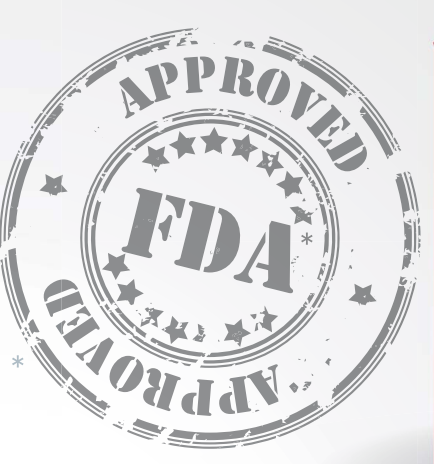

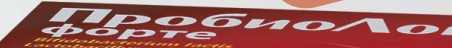 \\ Пробио^ог ФOPTE}

Bifidobacterium lactis

Lactobacillus acidophilus

Защищенные

кислотоустойчивой

СПОСОБСТВУЕт

ВОССТАНОВАЕНИЮ БАЛАНС

and SAANOLL

\section{В среднем 2,5 млрд. бактерий}

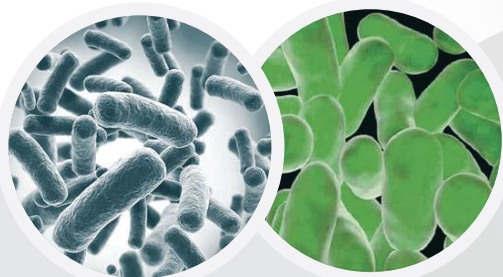

Бифидо и лактобактерии относятся к облигатной микрофлоре и занимают доминирующее положение в толстом кишечнике, составляя $90-95 \%$ от всех микроорганизмов кишечника 2

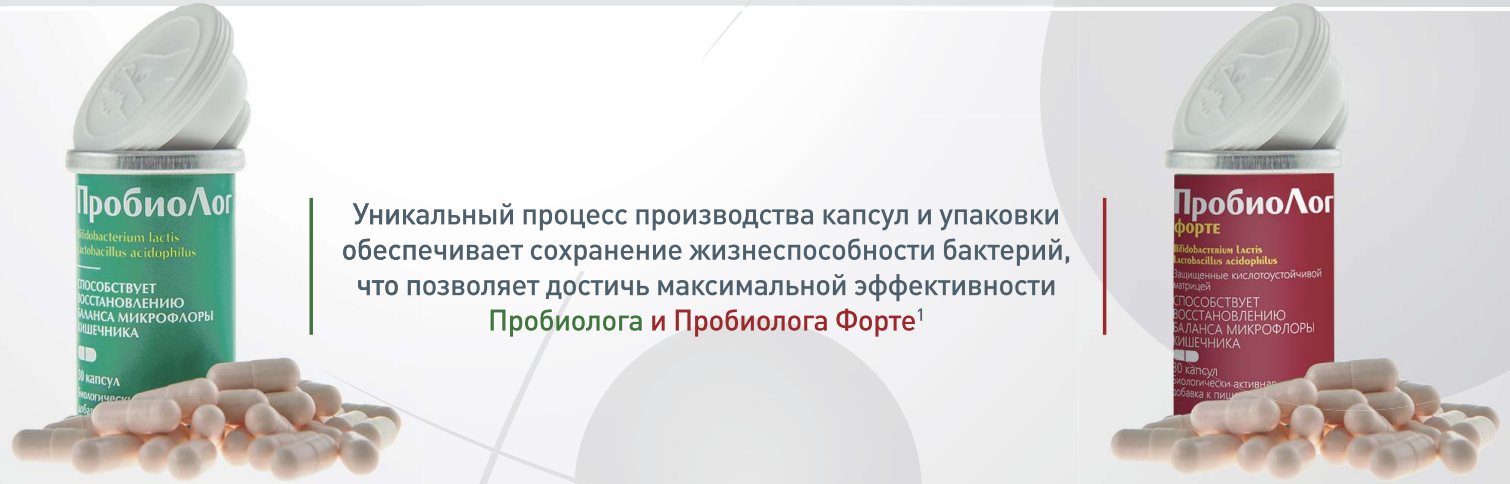

1. Инструкции по применению Пробиолога и Пробиолога Форте

2. С.В. Бельмер, А. В. Малкоч Кишечная микрофлора и значение пребиотиков

для ее функционирования Лечащий врач №4 2006

" Одобрено управлением по контролю за продуктами и лекарствами США

** Произведено в Европе

MAYOLY SPINDLER
ООО «МАЙОЛИ СПИНДЛЕР»

127051 Москва, ул. Садовая-Самотёчная, д. 24/27

Тел:+7 (495) 664-83-03. E-mail: voprosamayoly-spindler.ru

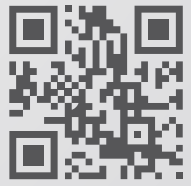


Таблица 3. Уровни доказательности Оксфордского центра медицины, основанной на доказательствах для оценки эффективности лечения применительно к вопросу «Помогло ли это лечение?»

Table 3. The levels of evidence of the Oxford Medical Centre based on the evidence for the assessment of treatment efficacy regarding the question "Was this treatment successful?"

\begin{tabular}{|c|c|}
\hline $\begin{array}{c}\text { Уровень доказательности } \\
\text { Level of evidence }\end{array}$ & $\begin{array}{c}\text { Тип исследования } \\
\text { Study type }\end{array}$ \\
\hline 1 & $\begin{array}{l}\text { Системный обзор рандомизированных исследований } \\
\text { Systemic review of randomised studies }\end{array}$ \\
\hline 2 & $\begin{array}{c}\text { Рандомизированное или обсервационное исследование, продемонстрировавшее } \\
\text { эффективность } \\
\text { Randomised or observational study, which demonstrated efficiency }\end{array}$ \\
\hline 3 & $\begin{array}{c}\text { Нерандомизированное контролируемое когортное исследование / динамическое } \\
\text { наблюдение } \\
\text { Non-randomised controlled cohort study/dynamic observation }\end{array}$ \\
\hline 4 & $\begin{array}{l}\text { Серии случаев, исследования «случай-контроль», контролируемые исследования } \\
\text { Case series, case-control studies, controlled studies }\end{array}$ \\
\hline 5 & $\begin{array}{l}\text { Обоснование механизма действия } \\
\text { Substantiation of action mechanisms }\end{array}$ \\
\hline
\end{tabular}

Таблица 4. Пробиотические штаммы, эффективные для лечения острой диареи

Table 4. Probiotic strains, effective for the treatment of acute diarrhea

\begin{tabular}{|c|c|c|c|c|}
\hline $\begin{array}{l}\text { Пробитический } \\
\text { штамм } \\
\text { Probiotic strain }\end{array}$ & $\begin{array}{l}\text { Рекомендуемая доза } \\
\text { Recommended dosage }\end{array}$ & $\begin{array}{c}\text { У ровень } \\
\text { доказательности } \\
\text { Level of evidence }\end{array}$ & $\begin{array}{l}\text { Комментарий } \\
\text { Comment }\end{array}$ & $\begin{array}{l}\text { Исследование } \\
\text { Study }\end{array}$ \\
\hline $\begin{array}{l}\text { Lactobacillus } \\
\text { rhamnosus GG }\end{array}$ & $\begin{array}{l}1 \times 10^{9} \mathrm{KOE} \times \\
2 \text { раза в день } \\
1 \times 10^{9} \mathrm{CFU} \times \\
2 \text { times a day }\end{array}$ & 3 & $\begin{array}{c}\text { Уменьшение } \\
\text { частоты стула } \\
\text { Decrease in stool } \\
\text { frequency }\end{array}$ & $\begin{array}{l}\text { E. Grossi et al., } \\
2010 \text { [23] }\end{array}$ \\
\hline $\begin{array}{l}\text { Saccharomyces } \\
\text { boulardii } \\
\text { CNCM I-745, } \\
\text { штамм S. cerevisiae }\end{array}$ & $\begin{array}{l}5 \times 10^{9} \mathrm{KOE} \times \\
2 \text { раза в день } \\
5 \times 10^{9} \mathrm{CFU} \times \\
2 \text { times a day }\end{array}$ & 2 & - & $\begin{array}{l}\text { S.J. Allen et } \\
\text { al., } 2010[24] \text {, } \\
\text { W. Höchter et } \\
\text { al., } 1990[25]\end{array}$ \\
\hline
\end{tabular}

Таблища 5. Пробиотические штаммы, эффективные для профилактики антибиотико-ассоциированной диареи

Table 5. Probiotic strains, effective for the prevention of antibiotic-associated diarrhea (AAD)

\begin{tabular}{|c|c|c|c|c|}
\hline $\begin{array}{c}\text { Пробитический } \\
\text { штамм } \\
\text { Probiotic strain }\end{array}$ & $\begin{array}{l}\text { Рекомендуемая доза } \\
\text { Recommended dosage }\end{array}$ & $\begin{array}{c}\text { Уровень } \\
\text { доказательности } \\
\text { Level of evidence }\end{array}$ & $\begin{array}{l}\text { Комментарий } \\
\text { Comment }\end{array}$ & $\begin{array}{l}\text { Исследование } \\
\text { Study }\end{array}$ \\
\hline $\begin{array}{l}\text { Lactobacillus } \\
\text { rhamnosus GG }\end{array}$ & $\begin{array}{l}10^{10} \mathrm{KOE} \times 2 \text { раза в день } \\
10^{10} \mathrm{CFU} \times 2 \text { times a day }\end{array}$ & 1 & \multirow{2}{*}{$\begin{array}{c}\text { Профилактика ААД } \\
\text { у амбулаторных } \\
\text { и госпитализированных } \\
\text { пациентов } \\
\text { AAD prevention } \\
\text { in outpatient and } \\
\text { hospitalised patients }\end{array}$} & $\begin{array}{l}\text { S. Hempel et } \\
\text { al., } 2012 \text { [26] }\end{array}$ \\
\hline $\begin{array}{l}\text { Saccharomyces } \\
\text { boulardii } \\
\text { CNCM I-745, } \\
\text { штамм S. cerevisiae }\end{array}$ & $\begin{array}{l}5 \times 10^{9} \mathrm{KOE} \times \\
2 \text { раза в день } \\
5 \times 10^{9} \mathrm{CFU} \times \\
2 \text { times a day }\end{array}$ & 1 & & $\begin{array}{l}\text { S. Hempel et } \\
\text { al., } 2012[26]\end{array}$ \\
\hline $\begin{array}{l}\text { Lactobacillus } \\
\text { reuteri DSM } 17938\end{array}$ & $\begin{array}{l}1 \times 10^{8} \text { КОЕ } \times \\
2 \text { раза в день } \\
1 \times 10^{8} \mathrm{CFU} \times \\
2 \text { times a day }\end{array}$ & 3 & $\begin{array}{c}\text { Профилактика ААД у } \\
\text { госпитализированных } \\
\text { пациентов } \\
\text { AAD prevention in hos- } \\
\text { pitalised patients }\end{array}$ & $\begin{array}{c}\text { L. Cimperman } \\
\text { et al., } 2011 \\
{[27]}\end{array}$ \\
\hline $\begin{array}{l}\text { Lactobacillus } \\
\text { acidophilus } \mathrm{NCFM} \\
\text { L. paracasei } \mathrm{Lpc}- \\
37, \text { Bifidobacterium } \\
\text { lactis } \mathrm{Bi}-07 \text {, } \\
\text { B. lactis } \mathrm{Bl}-04\end{array}$ & $\begin{array}{l}1,7 \times 10^{10} \mathrm{KOE} \text { в день } \\
1,7 \times 10^{10} \mathrm{CFU} \text { per day }\end{array}$ & 2 & $\begin{array}{c}\text { Профилактика ААД у } \\
\text { госпитализированных } \\
\text { пациентов } \\
\text { AAD prevention in hos- } \\
\text { pitalised patients }\end{array}$ & $\begin{array}{c}\text { A.C. } \\
\text { Ouwehand et } \\
\text { al., 2014 [28] }\end{array}$ \\
\hline
\end{tabular}


Продолжение таблищы 5

\begin{tabular}{|c|c|c|c|c|}
\hline $\begin{array}{c}\text { Пробитический } \\
\text { штамм } \\
\text { Probiotic strain }\end{array}$ & $\begin{array}{l}\text { Рекомендуемая доза } \\
\text { Recommended dosage }\end{array}$ & $\begin{array}{c}\text { Уровень } \\
\text { доказательности } \\
\text { Level of evidence }\end{array}$ & $\begin{array}{c}\text { Комментарий } \\
\text { Comment }\end{array}$ & $\begin{array}{l}\text { Исследование } \\
\text { Study }\end{array}$ \\
\hline $\begin{array}{l}\text { Lactobacillus } \\
\text { acidophilus LA-5, } \\
\text { Bifidumbacterium } \\
\text { animalis ssp. Lactis } \\
\text { BB-12 }\end{array}$ & $\begin{array}{l}2 \times 10^{9} \text { КОЕ } \times \\
2 \text { раза в день } \\
2 \times 10^{9} \mathrm{CFU} \times \\
2 \text { times a day }\end{array}$ & 2 & $\begin{array}{c}\text { Сокращение длитель- } \\
\text { ности и уменьшение } \\
\text { тяжести диареи на фоне } \\
\text { приема амоксициллина } \\
\text { или цефадроксила } \\
\text { Decrease of duration } \\
\text { and severity of diarrhea } \\
\text { against the background } \\
\text { of amoxicillin or } \\
\text { cefadroxil administration }\end{array}$ & $\begin{array}{c}\text { S. Chatterjee } \\
\text { et al., 2013 } \\
{[29]}\end{array}$ \\
\hline
\end{tabular}

Таблища 6. Пробиотические штаммы, эффективные для профилактики C. difficile-ассоциированной болезни

Таблица 6. Probiotic strains, effective for the prevention of C. difficile-associated disease

\begin{tabular}{|c|c|c|c|}
\hline $\begin{array}{l}\text { Пробитический штамм } \\
\text { Probiotic strain }\end{array}$ & $\begin{array}{l}\text { Рекомендуемая доза } \\
\text { Recommended dosage }\end{array}$ & $\begin{array}{l}\text { Уровень доказательности } \\
\text { Level of evidence }\end{array}$ & $\begin{array}{l}\text { Исследование } \\
\text { Study }\end{array}$ \\
\hline $\begin{array}{l}\text { Saccharomyces boulardii } \\
\text { CNCM I-745, штамм } \\
\text { S. cerevisiae }\end{array}$ & $\begin{array}{l}5 \times 10^{9} \mathrm{KOE} \times 2 \text { раза в день } \\
5 \times 10^{9} \mathrm{CFU} \times 2 \text { times a day }\end{array}$ & 3 & $\begin{array}{c}\text { J.Z Goldenberg et al., } \\
2013[30]\end{array}$ \\
\hline
\end{tabular}

Таблица 7. Пробиотические штаммы, увеличивающие эффективность эрадикационной терапии инфекции $H$. pylori

Table 7. Probiotic strains promoting the efficacy of H. pylori infection eradication

\begin{tabular}{|c|c|c|c|c|}
\hline $\begin{array}{c}\text { Пробитический } \\
\text { штамм } \\
\text { Probiotic strain }\end{array}$ & $\begin{array}{l}\text { Рекомендуемая доза } \\
\text { Recommended } \\
\text { dosage }\end{array}$ & $\begin{array}{c}\text { Уровень } \\
\text { доказательности } \\
\text { Level of evidence }\end{array}$ & $\begin{array}{c}\text { Комментарий } \\
\text { Comment }\end{array}$ & $\begin{array}{c}\text { Исследование } \\
\text { Study }\end{array}$ \\
\hline $\begin{array}{l}\text { Lactobacillus } \\
\text { rhamnosus GG }\end{array}$ & $\begin{array}{c}6 \times 10^{9} \text { КОЕ } \times \\
2 \text { раза в день*; } \\
6 \times 10^{9} \mathrm{CFU} \times \\
2 \text { times a day*; } \\
1 \times 10^{8}-10^{9} \text { КOE } \times \\
2 \text { раза в день } \\
1 \times 10^{8}-10^{9} \mathrm{CFU} \times \\
2 \text { times a day }\end{array}$ & 2 & $\begin{array}{c}\text { * Уменьшение побочных } \\
\text { эффектов при терапии } \\
\text { первой линии } \\
\text { * Decrease in adverse effects } \\
\text { during the first line therapy }\end{array}$ & $\begin{array}{l}\text { Y. Dang et } \\
\text { al., 2014 [32], } \\
\text { V. Ojetti et } \\
\text { al., } 2012 \text { [33] }\end{array}$ \\
\hline $\begin{array}{l}\text { Saccharomyces } \\
\text { boulardii CNCM } \\
\text { I-745, umaмм } S . \\
\text { cerevisiae }\end{array}$ & $\begin{array}{l}5 \times 10^{9} \mathrm{KOE} \times 2 \text { раза } \\
\text { в день } \\
5 \times 10^{9} \mathrm{CFU} \times 2 \text { times } \\
\text { a day }\end{array}$ & 1 & $\begin{array}{c}\text { Уменьшение побочных } \\
\text { эффектов при } \\
\text { эрадикационной терапии } \\
\text { Decrease in adverse effects } \\
\text { during the eradication } \\
\text { therapy }\end{array}$ & $\begin{array}{l}\text { Y. Dang et } \\
\text { al., } 2014 \text { [32] }\end{array}$ \\
\hline $\begin{array}{l}\text { Lactobacillus } \\
\text { reuteri DSM } 17938\end{array}$ & $\begin{array}{l}1 \times 10^{8} \mathrm{KOE} \times 3 \text { раза } \\
\text { в день } \\
1 \times 10^{8} \mathrm{CFU} \times 3 \text { times } \\
\text { a day }\end{array}$ & 2 & $\begin{array}{c}\text { Уменьшение побочных } \\
\text { эффектов при терапии вто- } \\
\text { рой линии с применением } \\
\text { левофлоксацина } \\
\text { Decrease in adverse effects } \\
\text { during the second line } \\
\text { therapy with levofloxacin }\end{array}$ & $\begin{array}{l}\text { V. Ojetti et } \\
\text { al., } 2012 \text { [33] }\end{array}$ \\
\hline
\end{tabular}

\subsection{3 Болезнь Крона}

Нет зарегистрированных в РФ штаммов

\section{5 Синдром раздраженного кишечника (СРК)}

Пробиотики уменьшают выраженность абдоминальной боли и вздутия живота, а также увеличи- вают показатели уровня качества жизни у пациентов с СРК (табл. 8).

\section{6 Функциональный запор}

Основным эффектом пробиотиков при функциональном запоре является увеличение кратности дефекации в неделю (табл. 9). 
Таблища 8. Пробиотические штаммы, эффективные при СРК

Table 8. Probiotic strains effective for the treatment of IBS

\begin{tabular}{|c|c|c|c|c|}
\hline $\begin{array}{l}\text { Пробиотический } \\
\text { штамм } \\
\text { Probiotic strain }\end{array}$ & $\begin{array}{l}\text { Рекомендуемая } \\
\text { доза } \\
\text { Recommended } \\
\text { dosage }\end{array}$ & $\begin{array}{l}\text { Уровень до- } \\
\text { казательности } \\
\text { Level of } \\
\text { evidence }\end{array}$ & $\begin{array}{l}\text { Комментарий } \\
\text { Comment }\end{array}$ & $\begin{array}{c}\text { Сылки } \\
\text { References }\end{array}$ \\
\hline $\begin{array}{l}\text { Lactobacillus } \\
\text { plantarum 299v } \\
(\text { DSM 9843) }\end{array}$ & $\begin{array}{c}1 \times 10^{10} \text { KOE } \times \\
1 \text { раз в день } \\
1 \times 10^{10} \text { CFU } \times \\
1 \text { time a day }\end{array}$ & 2 & $\begin{array}{c}\text { Уменьшение выраженности } \\
\text { боли в животе } \\
\text { Decrease in abdominal pain } \\
\text { intensity }\end{array}$ & $\begin{array}{l}\text { P. Ducrotté et } \\
\text { al., } 2012[34] \text {, } \\
\text { A.C. Ford et } \\
\text { al., } 2014[35]\end{array}$ \\
\hline $\begin{array}{l}\text { Saccharomyces } \\
\text { boulardii CNCM } \\
\text { I-745, wmaмm } \\
\text { S. cerevisiae } \\
\end{array}$ & $\begin{array}{l}5 \times 10^{9} \text { КОЕ } \times \\
2 \text { раза в день } \\
5 \times 10^{9} \mathrm{CFU} \times \\
2 \text { times a day }\end{array}$ & 2 & $\begin{array}{c}\text { Улучшение качества жизни } \\
\text { пациентов с CPК } \\
\text { Improvement in the quality of } \\
\text { life of IBS patients }\end{array}$ & $\begin{array}{l}\text { C.H. Choi et } \\
\text { al., } 2011 \text { [36] }\end{array}$ \\
\hline $\begin{array}{l}\text { Bifidobacterium } \\
\text { longum (infantis) } \\
35624\end{array}$ & $\begin{array}{l}1 \times 10^{8} \text { КОЕ } \times \\
1 \text { раз в день } \\
1 \times 10^{8} \text { CFU } \times \\
1 \text { time a day }\end{array}$ & 2 & $\begin{array}{c}\text { Субъективное уменьшение } \\
\text { общих симптомов СРК } \\
\text { Subjective decrease in general } \\
\text { IBS symptoms }\end{array}$ & $\begin{array}{l}\text { P.J. Whorwell } \\
\text { et al., } 2006 \text { [37], } \\
\text { P. Moayyedi et } \\
\text { al., } 2010 \text { [38] }\end{array}$ \\
\hline $\begin{array}{l}\text { Lactobacillus } \\
\text { animalis lactis } \\
\text { ВВ12, Lactobacillus } \\
\text { acidophilus LA-5, } \\
\text { Lactobacillus } \\
\text { delbrueckii подвид } \\
\text { bulgaricus LBY-27, } \\
\text { Streptococcus } \\
\text { thermophilus STY-31 }\end{array}$ & $\begin{array}{l}4 \times 10^{9} \text { КОЕ } \times \\
2 \text { раза в день } \\
4 \times 10^{9} \mathrm{CFU} \times \\
2 \text { times a day }\end{array}$ & 3 & $\begin{array}{c}\text { Уменьшение выраженности } \\
\text { абдоминальной боли } \\
\text { и метеоризма } \\
\text { Decrease in abdominal pain } \\
\text { intensity and meteorism }\end{array}$ & $\begin{array}{l}\text { E. Jafari et al., } \\
2014 \text { [39] }\end{array}$ \\
\hline $\begin{array}{l}\text { Lactobacillus } \\
\text { plantarum CECT } \\
7484, \text { Lactobacillus } \\
\text { plantarum } \\
\text { CECT } 7485, \\
\text { Pediococcus } \\
\text { acidilactici } \\
\text { CECT } 7483\end{array}$ & $\begin{array}{c}(1-2) \times 10^{9} \mathrm{KOE} \\
\text { в день (каждого } \\
\text { штамма) } \\
(1-2) \times 10^{9} \mathrm{CFU} \\
\text { per day (of each } \\
\text { strain) }\end{array}$ & 2 & $\begin{array}{c}\text { Улучшение качества жизни } \\
\text { пациентов с CPK (опросник } \\
\text { IBS-QoL) } \\
\text { Improvement in the quality of } \\
\text { life of IBS patients (IBS-QoL } \\
\text { questionnaire) }\end{array}$ & $\begin{array}{l}\text { V. Lorenzo- } \\
\text { Zúñiga et al., } \\
2014 \text { [40] }\end{array}$ \\
\hline $\begin{array}{l}\text { Bifidobacterium } \\
\text { bifidum, } \\
\text { B. longum, } \\
\text { B. infantis, } \\
\text { Lactobacillus } \\
\text { rhamnosus } \\
\text { (Флорасан-D) }\end{array}$ & $\begin{array}{c}1 \text { капсула } \\
(250 \text { мг }) \times \\
2 \text { раза в день } \\
1 \text { capsule } \\
(250 \mathrm{mg}) \times \\
2 \text { times a day }\end{array}$ & 2 & $\begin{array}{c}\text { Уменьшение клинических } \\
\text { симптомов и устранение } \\
\text { синдрома избыточного } \\
\text { бактериального роста у } \\
\text { пациентов с СРК с запором } \\
\text { Decrease in clinical symptoms } \\
\text { and elimination of bacterial } \\
\text { overgrowth syndrome in IBS } \\
\text { patients with constipation }\end{array}$ & $\begin{array}{l}\text { V. Ivashkin et } \\
\text { al., } \\
2015[41]\end{array}$ \\
\hline
\end{tabular}

Таблица 9. Пробиотические штаммы, эффективные при функциональном запоре

Table 9. Probiotic strains effective for the treatment of functional constipation

\begin{tabular}{|l|c|c|c|}
\hline $\begin{array}{c}\text { Пробитический штамм } \\
\text { Probiotic strain }\end{array}$ & $\begin{array}{c}\text { Рекомендуемая доза } \\
\text { Recommended dosage }\end{array}$ & $\begin{array}{c}\text { Уровень доказательности } \\
\text { Level of evidence }\end{array}$ & $\begin{array}{c}\text { Ссылки } \\
\text { References }\end{array}$ \\
\hline $\begin{array}{l}\text { Lactobacillus reuteri } \\
\text { DSM 17938 }\end{array}$ & $\begin{array}{c}1 \times 10^{8} \mathrm{KOE} \times 2 \text { paза в день } \\
1 \times 10^{8} \mathrm{CFU} \times 2 \text { times a day }\end{array}$ & 3 & V. Ojetti et al., \\
2014 [42]
\end{tabular}

\section{Заключение}

Изменения в составе кишечной микробиоты оказывают влияние на формирование симптомов заболеваний различных органов и систем.

Для профилактики и увеличения эффективности лечения пациентов, страдающих заболеваниями желудочно-кишечного тракта, широко применяются пробиотики.
Практические рекомендации по применению пробиотиков для лечения и профилактики заболеваний гастроэнтерологического профиля у взрослых разработаны для выбора оптимального пробиотического штамма, способствующего предотвращению или более быстрому обратному развитию симптомов определенного заболевания. 
Литература / References

1. World Gastroenterology Organisation. Probiotics and prebiotics. 2017. https://www.worldgastroenterology.org/ guidelines

2. Markowiak P., Śliżewska K. Effects of Probiotics, Prebiotics, and Synbiotics on Human Health. Nutrients. 2017;9(9):1021. DOI: 10.3390/nu9091021

3. Davani-Davari D., Negahdaripour M., Karimzadeh M., Seifan M., Mohkam M., Masoumi S. J., et al. Prebiotics: Definition, Types, Sources, Mechanisms, and Clinical Applications. Foods. 2019;8(3):92. DOI: 10.3390/foods8030092

4. Pandey K.R., Naik S.R., Vakil B.V. Probiotics, prebiotics and synbiotics - a review. J Food Sci Technol. 2015;52(12):7577-87. DOI: 10.1007/s13197-015-1921-1

5. Plaza-Diaz J., Ruiz-Ojeda F.J., Gil-Campos M., Gil A. Mechanisms of Action of Probiotics. Adv Nutr. 2019;10(Suppl 1):S49-66. DOI: 10.1093/advances/nmy063

6. Halloran K., Underwood M.A. Probiotic mechanisms of action. Early Hum Dev. 2019;135:58-65. DOI: 10.1016/j. earlhumdev.2019.05.010

7. Canfora E.E., Jocken J.W., Blaak E.E. Short-chain fatty acids in control of body weight and insulin sensitivity. Nat Rev Endocrinol. 2015;11(10):577-91. DOI: 10.1038/ nrendo.2015.128

8. Strandwitza $P$. Neurotransmitter modulation by the gut microbiota. Brain Res. 2018;1693(Pt B):128-33. DOI: $10.1016 /$ j.brainres.2018.03.015

9. de Moreno de LeBlanc A., Levit R., de Giori G.S., LeB lanc J.G. Vitamin Producing Lactic Acid Bacteria as Complementary Treatments for Intestinal Inflammation. Antiinflamm Antiallergy Agents Med Chem. 2018;17(1):50-56. DOI: $10.2174 / 1871523017666180502170659$

10. Halloran K., Underwood M.A. Probiotic mechanisms of action. Early Hum Dev. 2019;135:58-65. DOI: 10.1016/j. earlhumdev.2019.05.010

11. Евразийская экономическая комиссия. Единые санитарно-эпидемиологические и гигиенические требования к продукции (товарам), подлежащей санитарно-эпидемиологическому надзору (контролю). Утверждены Решением Комиссии таможенного союза от 28 мая 2010 года № 299. [Eurasian Economic Commission. Uniform Sanitary Epidemiological and Hygienic Requirements for the Goods Subject to Sanitary and Epidemiological Supervision (Control). Approved by the Decision of the Customs Union Commission No. 299 dd. May 28, 2010 (In Russ.)] http://www.eurasiancommission.org/ru/act/texnreg/ depsanmer/sanmeri/Pages/P2_299.aspx

12. Федеральная служба по надзору в сфере защиты прав потребителей и благополучия человека. Что нужно знать о биологически активных добавках к пище. Информационный бюллетень 12.05.2019 ə. [Federal Service for Surveillance on Consumer Rights Protection and $\mathrm{Hu}-$ man Wellbeing. What you need to know about dietary supplements. Newsletter 12.05.2019 (In Russ.)] https:// www.rospotrebnadzor.ru/about/info/news/news_details. php? ELEMENT ID $=11900$

13. TP TC $021 / 201 \overline{1}$ Технический регламент Таможенного союза «О безопасности пищевой продукции» от 9 декабря 2011 года № 880. [TR TS 021/2011 Technical Regulation of the Customs Union No 880 of December 9, 2011 "On Food Safety" (In Russ.)] http://old.gost.ru/wps/ portal/pages/main

14. Федеральный закон РФ от 12 апреля 2010 г. № 61-Ф3 «Об обращении лекарственных средств». [Federal Law No. 61-FZ on the Circulation of Medicines of April 12, 2010 (In Russ.)] https://rg.ru/2010/04/14/lekarstvadok.html

15. Приказ Министерства здравоохранения РФ от 11 июля 2017 г. № 403н «Об утверждении правил отпуска лекарственных препаратов для медицинского применения, в том числе иммунобиологических лекарственных препаратов, аптечными организациями, индивидуальными предпринимателями, имеющими лицензию на фармацевтическую деятельность» от 12 сентября 2017. [Order of the Ministry of Healthcare of the Russian Fed- eration No 403n "On approval of the rules for dispensing drugs for medical use, including immunobiological drugs, by pharmacy organisations, individual entrepreneurs licensed for pharmaceutical activities" of July 11, 2017 (In Russ.)] https://rg.ru/2017/09/12/minzdrav-prikaz403site-dok.html

16. Общая фармакопейная статья «Пробиотики» ОФС.1.7.1.0008.15 Министерства Здравоохранения PФ. [General Pharmacopoeial Monograph "Probiotics" OFS.1.7.1.0008.15 of the Ministry of Healthcare of the Russian Federation (In Russ.)] http://femb.ru/femb/ pharmacopea.php

17. Shi L.H., Balakrishnan K., Thiagarajah K., Mohd Ismail N. I., Yin O.S. Beneficial Properties of Probiotics. Trop Life Sci Res. 2016;27(2):73-90. DOI: 10.21315/ tlsr2016.27.2.6

18. Ishibashi N., Yamazaki S. Probiotics and safety. Am J Clin Nutr. 2001;73(2 Suppl):465S-70S. DOI: 10.1093/ ajcn $/ 73.2 .465 \mathrm{~s}$

19. de Vos P., Faas M.M., Spasojevic M.M., Sikkema J. Encapsulation for preservation of functionality and targeted delivery of bioactive food components. Int Dairy J. 2010;20:292-302. DOI: 10.1016/j.idairyj.2009.11.008

20. Burgain J., Gaiani C., Linder M., Scher J. Encapsulation of probiotic living cells: from laboratory scale to industrial applications. J Food Eng. 2011;104:467-83. DOI: 10.1016/j.jfoodeng.2010.12.031

21. Salas-Jara M., Ilabaca A., Vega M., García A. Biofilm forming Lactobacillus: new challenges for the development of probiotics. Microorganisms. 2016;4:35. DOI: $10.3390 /$ microorganisms 4030035

22. Howick J., Chalmers I., Glasziou P., Greenhalgh T., Heneghan C., Liberati A., et al. "Explanation of the 2011 Oxford Centre for Evidence-Based Medicine (OCEBM) Levels of Evidence (Background Document)". Oxford Centre for Evidence-Based Medicine. https://www.cebm. net $/$ index.aspx $? \mathrm{o}=5653$

23. Grossi E., Buresta R., Abbiati R., Cerutti R., Pro-DIA study group. Clinical trial on the efficacy of a new symbiotic formulation, Flortec, in patients with acute diarrhea: a multicenter, randomized study in primary care. J Clin Gastroenterol. 2010;44 Suppl 1:S35-41. DOI: 10.1097/ MCG.0b013e3181e103f4

24. Allen S.J., Martinez E.G., Gregorio G.V., Dans L.F. Probiotics for treating acute infectious diarrhoea. Cochrane Database Syst Rev. 2010;(11):CD003048. DOI: 10.1002/14651858.CD003048.pub3

25. Höchter W., Hagenhoff G. Saccharomyces boulardii in acute adult diarrhea: efficacy and tolerability of treatment. Munch Med Wochenschr. 1990;(132):188-92.

26. Hempel S., Newberry S.J., Maher A.R., Wang Z., Miles J.N.V., Shanman R., et al. Probiotics for the prevention and treatment of antibiotic-associated diarrhea: a systematic review and meta-analysis. JAMA. 2012;307(18):1959-69. DOI: 10.1001/jama.2012.3507

27. Cimperman L., Bayless G., Best K., Diligente A., Mordarski B., Oster M., et al. A randomized, double-blind, placebo-controlled pilot study of Lactobacillus reuteri ATCC 55730 for the prevention of antibiotic-associated diarrhea in hospitalized adults. J Clin Gastroenterol. 2011;45(9):7859. DOI: $10.1097 /$ MCG.0b013e3182166a42

28. Ouwehand A.C., DongLian C., Weijian X., Stewart M., Ni J., Stewart T., Miller L.E. Probiotics reduce symptoms of antibiotic use in a hospital setting: a randomized dose response study. Vaccine. 2014 Jan 16;32(4):458-63. DOI: $10.1016 /$ j.vaccine.2013.11.053

29. Chatterjee S., Kar P., Das T., Ray S., Gangulyt S., Rajendiran C., Mitra M. Randomised placebo-controlled double blind multicenteric trial on efficacy and safety of Lactobacillus acidophilus LA-5 and Bifidobacterium BB-12 for prevention of antibiotic-associated diarrhoea. J Assoc Physicians India. 2013 Oct;61(10):708-12.

30. Goldenberg J.Z., Yap C., Lytoyn L., Lo C.K., Beardsley J., Mertz D., Johnston B.C. Probiotics for the preven- 
tion of Clostridium difficile-associated diarrhea in adults and children. Cochrane Database Syst Rev. 2013;5:CD006095. DOI: 10.1002/14651858.CD006095.pub4

31. Shi X., Zhang J., Mo L., Shi J., Qin M., Huang X. Efficacy and safety of probiotics in eradicating Helicobacter pylori. A network meta-analysisMedicine (Baltimore). 2019;98(15):e15180. DOI: 10.1097/ MD.0000000000015180

32. Dang Y., Reinhardt J.D., Zhou X., Zhang G. The ef fect of probiotics supplementation on Helicobacter pylori eradication rates and side effects during eradication therapy: a meta-analysis. PloS One. 2014;9(11):e111030. DOI: 10.1371/journal.pone.0111030

33. Ojetti V., Bruno G., Ainora M.E., Gigante G., Rizzo G., Roccarina D., Gasbarrini A. Impact of Lactobacillus reuteri Supplementation on Anti-Helicobacter pylori Levofloxacin-Based Second-Line Therapy. Gastroenterol Res Pract. 2012;2012:740381. DOI: 10.1155/2012/740381

34. Ducrotté P., Sawant P., Jayanthi $V$. Clinical trial: Lactobacillus plantarum 299v (DSM 9843) improves symptoms of irritable bowel syndrome. World J Gastroenterol 2012;18(30):4012-8. DOI: 10.3748/wjg.v18.i30.4012

35. Ford A.C., Quigley E.M., Lacy B.E., Lembo A.J., Saito Y.A., Schiller L.R., et al. Efficacy of prebiotics, probiotics, and synbiotics in irritable bowel syndrome and chronic idiopathic constipation: systematic review and meta-analysis. Am J Gastroenterol. 2014;109(10):1547-61; quiz 1546, 1562. DOI: 10.1038/ajg.2014.202

36. Choi C.H., Jo S.Y., Park H.J., Chang S.K., Byeon J.S., Myung S.J. A randomized, double-blind, placebo-controlled multicenter trial of saccharomyces boulardii in irritable bowel syndrome: effect on quality of life. J Clin Gastroenterol. 2011;45(8):679-83. DOI: 10.1097 MCG.0b013e318204593e

\section{Сведения об авторах}

Ивашкин Владимир Трофимович - доктор медицинских наук, академик РАН, профессор, заведующий кафедрой пропедевтики внутренних болезней Института клинической медицины им. Н.В. Склифосовского ФГАОУ ВО «Первый Московский государственный медицинский университет им. И.М. Сеченова» (Сеченовский университет) Министерства здравоохранения Российской Федерации. Контактная информация: kont087@mail.ru;

119435, г. Москва, ул. Погодинская, д. 1, стр. 1.

ORCID: https://orcid.org/0000-0002-6815-6015

Маев Игорь Вениаминович - доктор медицинских наук, академик РАН, профессор, заведующий кафедрой пропедевтики внутренних болезней и гастроэнтерологии ФГБОУ ВО «Московский государственный медико-стоматологический университет им. А.И. Евдокимова».

Контактная информация: igormaev@rambler.ru;

127473, г. Москва, ул. Делегатская, д. 20, стр. 1

ORCID: https://orcid.org/0000-0001-6114-564X

Абдулганиева Диана Ильдаровна - доктор медицинских наук, зав. кафедрой госпитальной терапии ФГБОУ ВО «Казанский государственный медицинский университет» Министерства здравоохранения Российской Федерации.

Контактная информация: Diana_s@mail.ru;

420012, г. Казань, ул. Бутлерова, д. 49.

ORCID: https://orcid.org/0000-0001-7069-2725

Алексеенко Сергей Алексеевич - доктор медицинских наук, заведующий кафедрой госпитальной терапии Дальневосточного государственного медицинского университета (ДВГМУ) Министерства здравоохранения Российской Федерации; руководитель Клиники внутренних болезней Дорожной клинической больницы на ст. Хабаровск-1 Дальневосточной железной дороги (ДВЖД).

Контактная информация: sa.alexeenko@gmail.com;

680000, г. Хабаровск, ул. Запарина, д. 83

ORCID: https://orcid.org/0000-0003-1724-9980
37. Whorwell P.J., Altringer L., Morel J., Bond Y., Charbonneau D., O'Mahony L., et al. Efficacy of an encapsulated probiotic Bifidobacterium infantis 35624 in women with irritable bowel syndrome. Am J Gastroenterol. 2006;101(7):1581-90. DOI: $10.1111 / \mathrm{j} .1572-$ $0241.2006 .00734 . \mathrm{x}$

38. Moayyedi P., Ford A.C., Talley N.J., Cremonini F., Foxx-Orenstein A.E., Brandt L.J., Quigley E.M. The efficacy of probiotics in the treatment of irritable bowel syndrome: a systematic review. Gut. 2010;59(3):325-32. DOI: $10.1136 /$ gut.2008.167270

39. Jafari E., Vahedi H., Merat S., Momtahen S., Riahi A. Therapeutic effects, tolerability and safety of a multi-strain probiotic in Iranian adults with irritable bowel syndrome and bloating. Arch Iran Med. 2014;17(7):466-70. DOI: $0141707 /$ AIM.003

40. Lorenzo-Zúñiga V., Llop E., Suárez C., Álvarez B., Abreu L., Espadaler J., Serra J. I.31, a new combination of probiotics, improves irritable bowel syndrome-related quality of life. World J Gastroenterol. 2014;20(26):870916. DOI: $10.3748 /$ wjg.v20.i26.8709

41. Ivashkin V., Drapkina O., Poluektova Ye., Kuchumova S., Sheptulin A., Shifrin O. The Effect of a Multistrain Probiotic on the Symptoms and Small Intestinal Bacterial Overgrowth in Constipation-predominant Irritable Bowel Syndrome: A Randomized, Simple-blind, Placebo-controlled Trial. American Journal of Clinical Medicine Research. 2015;3(2):18-23. DOI: 10.12691/ajcmr-3-2-1

42. Ojetti V., Ianiro G., Tortora A., D'Angelo G., Di Rienzo T.A., Bibbò $S$., et al. The effect of Lactobacillus reuteri supplementation in adults with chronic functional constipation: a randomized, double-blind, placebo-controlled trial. J Gastrointest Liver Dis JGLD. 2014;23(4):387-91. DOI: 10.15403/jgld.2014.1121.234.elr

\section{Information about the authors}

Vadimir T. Ivashkin - Dr. Sci. (Med.), RAS Academician, Prof., Departmental Head, Department of Propaedeutics of Internal Diseases, N.V. Sklifosovsky Institute of Clinical Medicine, Sechenov First Moscow State Medical University (Sechenov University).

Contact information: kont07@yandex.ru;

119435, Moscow, Pogodinskaya str., 1, bld. 1.

ORCID: https://orcid.org/0000-0002-6815-6015

Igor V. Mayev - Dr. Sci. (Med.), RAS Academician, Prof., Departmental Head, Department of Internal Diseases Propedeutics and Gastroenterology, A.I. Yevdokimov Moscow State University of Medicine and Dentistry.

Contact information: igormaev@rambler.ru

127473, Moscow, Delegatskaya str., 20, bld. 1.

ORCID: https://orcid.org/0000-0001-6114-564X

Diana I. Abdulganieva - Dr. Sci. (Med.), Departmental Head, Department of Hospital Therapy, Kazan State Medical University.

Contact information: Diana s@mail.ru;

420012, Kazan, Butlerova str., 49.

ORCID: https://orcid.org/0000-0001-7069-2725

Sergey A. Alekseenko - Dr. Sci. (Med.), Departmental Head, Department of Hospital Therapy, Far Eastern State Medical University, Head, Clinic of Internal Diseases, Road clinical hospital of the Khabarovsk-1 station of the Far Eastern railroad (FERR)

Contact information: sa.alexeenko@gmail.com;

680000, Khabarovsk, Zaparina str., 83.

ORCID: https://orcid.org/0000-0003-1724-9980 
Ивашкина Наталья Юрьевна - доктор медицинских наук, доцент кафедры пропедевтики внутренних болезней и гастроэнтерологи ФГБОУ ВО «Московский государственный медико-стоматологический университет им. А.И. Евдокимова» Министерства здравоохранения Российской Федерации. Контактная информация: akliha@bk.ru;

127473, г. Москва, ул. Делегатская, д. 20, стр. 1.

ORCID: https://orcid.org/0000-0002-0847-9234

Корочанская Наталья Всеволодовна - доктор медицинских наук, ФГБОУ ВО «Кубанский государственный медицинский университет» Министерства здравоохранения Российской Федерации; ГБУЗ «Краевая клиническая больница № 2» Министерства здравоохранения Краснодарского края. Контактная информация: nvk-gastro@mail.ru;

350012, г. Краснодар, ул. Красных Партизан, д. 6, корпус 2. ORCID: https://orcid.org/0000-0002-5538-9418

Маммаев Сулейман Нураттинович - доктор медицинских наук, профессор, заведующий кафедрой госпитальной терапии № 1, ректор ФГБОУ ВО «Дагестанский государственный медицинский университет» Министерства здравоохранения Российской Федерации.

Контактная информация: hepar-sul-dag@mail.ru,

367000 Республика Дагестан, г. Махачкала, пл. Ленина, д. 1. ORCID: https://orcid.org/0000-0001-8898-8831

Полуэктова Елена Александровна - доктор медицинских наук, профессор кафедры пропедевтики внутренних болезней Института клинической медицины им. Н.В. Склифосовского ФГАОУ ВО «Первый Московский государственный медицинский университет им. И.М. Сеченова» (Сеченовский университет) Министерства здравоохранения Российской Федерации.

Контактная информация: polouektova@rambler.ru;

119991, г. Москва, ул. Погодинская, д. 1, стр. 1.

ORCID: https://orcid.org/0000-0003-1312-120X

Трухманов Александр Сергеевич - доктор медицинских наук, профессор кафедры пропедевтики внутренних болезней Института клинической медицины им. Н.В. Склифосовского ФГАОУ ВО «Первый Московский государственный медицинский университет им. И.М. Сеченова» (Сеченовский университет) Министерства здравоохранения Российской Федерации.

Контактная информация: alexander.trukhmanov@gmail.com; 119991, г. Москва, ул. Погодинская, д. 1, стр. 1.

ORCID: https://orcid.org/0000-0003-3362-2968

Успенский Юрий Павлович - профессор, доктор медицинских наук, заведующий кафедрой факультетской терапии им. Профессора В.А. Вальдмана ФГБОУ ВО «Санкт-Петербургский государственный педиатрический медицинский университет» Министерства здравоохранения Российской Федерации; главный гастроэнтеролог СанктПетербурга.

Контактная информация: uspenskiy65@mail.ru;

194100, Санкт-Петербург, ул. Литовская, д. 2.

ORCID: https://orcid.org/0000-0001-6434-1267

Цуканов Владислав Владимирович - профессор, доктор медицинских наук, заведующий Клиническим отделением патологии пищеварительной системы у взрослых и детей Научно-исследовательского института медицинских проблем Севера (НИИ МПС), г. Красноярск; главный гастроэнтеролог Сибирского федерального округа (СФО).

Контактная информация: gastro@impn.ru;

660022, г. Красноярск, ул. Партизана Железняка, д. Зг.

ORCID: https://orcid.org/0000-0002-9980-2294
Natalya Yu. Ivashkina - Dr. Sci. (Med.), Assoc. Prof., Department of Internal Diseases Propedeutics and Gastroenterology, A.I. Yevdokimov Moscow State University of Medicine and Dentistry.

Contact information: akliha@bk.ru;

127473, Moscow, Delegatskaya str., 20, bld. 1.

ORCID: https://orcid.org/0000-0002-0847-9234

Natalya V. Korochanskaya - Dr. Sci. (Med.), Kuban State Medical University, Regional Clinical Hospital No. 2. Contact information: nvk-gastro@mail.ru;

350012, Krasnodar, Krasnykh Partizan str., 6 bld. 2.

ORCID: https://orcid.org/0000-0002-5538-9418

Suleyman N. Mammaev - Dr. Sci. (Med.), Prof., Departmental Head, Department of Hospital Therapy No. 1, Rector, Dagestan State Medical University.

Contact information: hepar-sul-dag@mail.ru,

367000 Republic of Dagestan, Makhachkala, Lenina sq., 1.

ORCID: https://orcid.org/0000-0001-8898-8831

Elena A. Poluektova - Dr. Sci. (Med.), Prof., Department of Internal Diseases Propedeutics, Gastroenterology and Hepatology, N.V. Sklifosovsky Institute of Clinical Medicine, I.M. Sechenov First Moscow State Medical University (Sechenov University).

Contact information: polouektova@rambler.ru;

119435, Moscow, Pogodinskaya str., 1, bld. 1

ORCID: https://orcid.org/0000-0003-1312-120X

Alexander S. Trukhmanov - Dr. Sci. (Med.), Prof., Internal Diseases Propedeutics Department, N.V. Sklifosovsky Institute of Clinical Medicine, I.M. Sechenov First Moscow State Medical University (Sechenov University).

Contact information: alexander.trukhmanov@gmail.com;

19991, Moscow, Pogodinskaya str., 1, bld. 1.

ORCID: https://orcid.org/0000-0003-3362-2968

Yury P. Uspensky - Dr. Sci. (Med.), Prof., Departmental Head, Department of Faculty Therapy named after V.A. Valdman, St. Petersburg State Pediatric Medical University, Principal Gastroenterologist.

Contact information: uspenskiy65@mail.ru;

194100, St. Petersburg, Litovskaya str., 2.

ORCID: https://orcid.org/0000-0001-6434-1267

Vladislav V. Tsukanov - Dr. Sci. (Med.), Prof., Departmental Head, Department of Digestive System Pathology in Adults and Children, Scientific Research Institute of Medical Problems of the North, Principal Gastroenterologist of Siberian Federal District.

Contact information: gastro@impn.ru;

660022, Krasnoyarsk, Partizana Zheleznyaka str., 3g.

ORCID: https://orcid.org/0000-0002-9980-2294 
Шифрин Олег Самуилович - доктор медицинских наук, профессор кафедры пропедевтики внутренних болезней Института клинической медицины им. Н.В. Склифосовского, заведующий отделением хронических заболеваний кишечника и поджелудочной железы Клиники пропедевтики внутренних болезней, гастроэнтерологии и гепатологии им. В.Х. Василенко ФГАОУ ВО «Первый Московский государственный медицинский университет им. И.М. Сеченова» (Сеченовский университет) Министерства здравоохранения Российской Федерации.

Контактная информация: oleg_shifrin@mail.ru;

119991, г. Москва, ул. Погодинская, д. 1, стр. 1.

ORCID: https://orcid.org/0000-0001-8148-2862

Зольникова Оксана Юрьевна - кандидат медицинских наук, доцент кафедры пропедевтики внутренних болезней Института клинической медицины им. Н.В. Склифосовского ФГАОУ ВО «Первый Московский государственный медицинский университет им. И.М. Сеченова» (Сеченовский университет) Министерства здравоохранения Российской Федерации.

Контактная информация: ks.med@mail.ru;

119991, г. Москва, ул. Погодинская, д. 1, стр. 1.

ORCID: https://orcid.org/0000-0002-6701-789X

Ивашкин Константин Владимирович - кандидат медицинских наук, доцент кафедры пропедевтики внутренних болезней Института клинической медицины им. Н.В. Склифосовского ФГАОУ ВО «Первый Московский государственный медицинский университет им. И.М. Сеченова» (Сеченовский университет) Министерства здравоохранения Российской Федерации.

Контактная информация: 2135833@mail.ru;

119991, г. Москва, ул. Погодинская, д. 1, стр. 1.

ORCID: https://orcid.org/0000-0002-5699-541X

Лапина Татьяна Львовна - кандидат медицинских наук, доцент кафедры пропедевтики внутренних болезней Института клинической медицины им. Н.В. Склифосовского ФГАОУ ВО «Первый Московский государственный медицинский университет им. И.М. Сеченова» (Сеченовский университет) Министерства здравоохранения Российской Федерации.

Контактная информация: tatlapina@gmail.com;

119991, г. Москва, ул. Погодинская, д. 1, стр. 1.

ORCID: https://orcid.org/0000-0003-4456-8725

Масленников Роман Вячеславович - кандидат медицинских наук, ассистент кафедры пропедевтики внутренних болезней Института клинической медицины им. Н.В. Склифосовского ФГАОУ ВО «Первый Московский государственный медицинский университет им. И.М. Сеченова» (Сеченовский университет) Министерства здравоохранения Российской Федерации; врач общей практики ГБУЗ г. Москвы «Консультативно-диагностический центр № 2 Департамента здравоохранения г. Москвы».

Контактная информация: mmmm00@yandex.ru;

119435, г. Москва, ул. Погодинская, д. 1, стр. 1.

ORCID: 0000-0001-7513-1636

Ульянин Анатолий Игоревич* - врач отделения хрониче ских заболеваний кишечника и поджелудочной железы Клиники пропедевтики внутренних болезней, гастроэнтерологии и гепатологии им. В.Х. Василенко, ФГАОУ ВО «Первый Московский государственный медицинский университет им. И.М. Сеченова» (Сеченовский университет) Министерства здравоохранения Российской Федерации. Контактная информация: dr.ulianin@gmail.com; 119991, г. Москва, ул. Погодинская, д. 1, стр. 1.

ORCID: https://orcid.org/0000-0001-5506-5555
Oleg S. Shifrin - Dr. Sci. (Med.), Prof., Propaedeutics of Internal Diseases Department, N.V. Sklifosovsky Institute of Clinical Medicine, Departmental Head, Department of Chronic Diseases of the Intestines and Pancreas, V.H. Vasilenko Clinic of the Propaedeutics of Internal Diseases, Gastroenterology and Hepatology, I.M. Sechenov First Moscow State Medical University (Sechenov University).

Contact information: oleg shifrin@mail.ru;

119435, Moscow, Pogodinskaya str., 1, bld. 1.

ORCID: https://orcid.org/0000-0001-8148-2862

Oxana Yu. Zolnikova - Cand. Sci. (Med.), Assoc. Prof., Propaedeutics of Internal Diseases Department, N.V. Sklifosovsky Institute of Clinical Medicine, I.M. Sechenov First Moscow State Medical University (Sechenov University).

Contact information: Ks.med@mail.ru,

119991, Moscow, Pogodinskaya str., 1, building 1.

ORCID: https://orcid.org/0000-0002-6701-789X

Konstantin V. Ivashkin - Cand. Sci. (Med.), Assoc. Prof., Department of Propaedeutics of Internal Diseases, N.V. Sklifosovsky Institute of Clinical Medicine, Sechenov First Moscow State Medical University (Sechenov University).

Contact information: 2135833@mail.ru;

119991, Moscow, Pogodinskaya str., 1, bld. 1

ORCID: https://orcid.org/0000-0002-5699-541X

Tatiana L. Lapina - Cand. Sci. (Med.), Assoc. Prof., Internal Diseases Propedeutics Department, N.V. Sklifosovsky Institute of Clinical Medicine, I.M. Sechenov First Moscow State Medical University (Sechenov University)

Contact information: tatlapina@gmail.com;

19991, Moscow, Pogodinskaya str., 1, bld. 1.

ORCID: https://orcid.org/0000-0003-4456-8725

Roman V. Maslennikov - Cand. Sci. (Med.), Assist., Department of Internal Diseases Propedeutics, Gastroenterology and Hepatology, N.V. Sklifosovsky Institute of Clinical Medicine, I.M. Sechenov First Moscow State Medical University (Sechenov University), General practitioner, Consulting and Diagnostic Centre No. 2 of the Moscow Department of Healthcare. Contact information: mmmm00@yandex.ru; 119435,

Moscow, Pogodinskaya str., 1, bld. 1

ORCID: 0000-0001-7513-1636

Anatoly I. Ulyanin* - Doctor, Department of Chronic Diseases of the Intestines and Pancreas, V.H. Vasilenko Clinic of the Propaedeutics of Internal Diseases, Gastroenterology and Hepatology, I.M. Sechenov First Moscow State Medical University (Sechenov University).

Contact information: dr.ulianin@gmail.com;

119991, Moscow, Pogodinskaya str., 1, bld. 1

ORCID: https://orcid.org/0000-0001-5506-5555

Поступила: 15.03.2019 Принята: 02.04.2019 Опубликована: 30.04.2020 Submitted: 15.03.2019 Accepted: 02.04.2019 Published: 30.04.2020

\footnotetext{
* Автор, ответственный за переписку / Corresponding author
} 